\title{
MRS Elects Officers, Councillors for 2001
}

Members of the Materials Research Society have elected two officers and six councillors to join the 2001 Council, which consists of the executive committee and 15 councillors. The annual election ended October 13, 2000.

\section{MRS Officers}

President

Martin L. Green (2001)

Bell Laboratories, Lucent Technologies

Immediate Past President

Harry A. Atwater (2001)

California Institute of Technology

Vice President (President Elect)

*Alex King (2001)

Purdue University

\section{Secretary}

Chuang Chuang Tsai (2001)

Applied Komatsu Technology

\section{Treasurer}

*Merrilea Mayo (2002)

Pennsylvania State University

\section{MRS Councillors}

*Eduard Arzt (2003)

Max Planck Institute

Orlando Auciello (2002)

Argonne National Laboratory

John W. Cahn (2001)

National Institute of Standards and Technology

Anthony K. Cheetham (2001)

University of California-Santa Barbara

*Peter F. Green (2003)

University of Texas-Austin

A. Lindsay Greer (2001)

Cambridge University

*Linda L. Horton (2003)

Oak Ridge National Laboratory

*Howard E. Katz (2003)

Lucent Technologies

Anne M. Mayes (2002)

Massachusetts Institute of Technology
*Paul S. Peercy (2003)

University of Wisconsin-Madison

Stephen J. Pennycook (2001)

Oak Ridge National Laboratory

Caroline A. Ross (2001)

Massachusetts Institute of Technology

Rudolf M. Tromp (2001)

IBM T.J. Watson Research Center

*Julia R. Weertman (2003)

Northwestern University

R. Stanley Williams (2002)

Hewlett-Packard Laboratories

(Terms of office expire at the end of the years indicated in parentheses.)

*Newly elected.

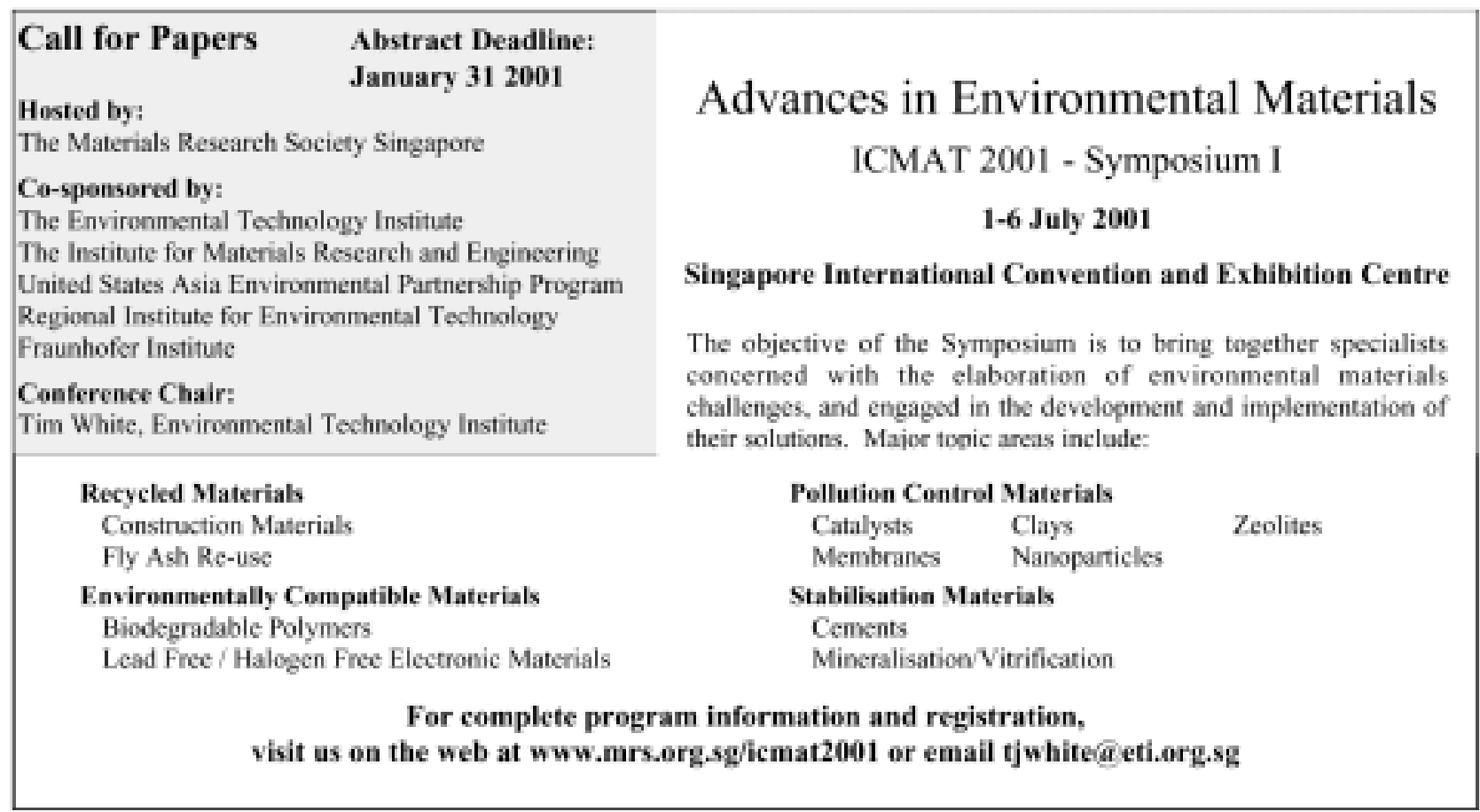

Circle No. 38 on Inside Back Cover 